\title{
LEDGF/p75 IN interaction inhibitors: in silico studies of an old target with novel approach
}

\author{
Amit M Pant, Rupesh V Chikhale, Sunil S Menghani, Pramod B Khedekar \\ From 2nd International Science Symposium on HIV and Infectious Diseases (HIV SCIENCE 2014) \\ Chennai, India. 30 January - 1 February 2014
}

\section{Background}

Despite development in Anti Retroviral Therapy (ART), reports of HIV infection remains in continuous momentum and a cure seems to be imaginary. Raltegravir, an Integrase (IN) inhibitor, provides some life expectancy to patients on salvage therapy. Nowadays, IN inhibitors reported with resistance and shows cross resistance to other drugs in this class. Human Lens Epithelium Derived Growth Factor (LEDGF)/p75 plays a vital role in the HIV life cycle and its importance has been shown in numerous studies. In the LEDGF/p75 IN complex, LEDGF binds to IN at a region other than the catalytic active site. Thus, we tried computationally to approach these IN-LEDGF interaction sites as a novel target in therapy.

\section{Methods}

The computational studies involved protein preparation, ligand preparation and energy minimization, grid generation, docking and analysis of results. A library of 396 molecules were prepared considering a pyrimidine ring as core. These operations were performed using Maestro, Discovery studio and VLife Sciences suites.

\section{Results}

It is known that Ile365 establishes a hydrogen bond with backbone carbonyl group of IN Gln 168 whereas Asp366 of LEDGF/p75 forms a hydrogen bond with Glu170, on similar basis it was found that AMP_1071 exhibits hydrogen bonding with Gln95 of one monomer and Gln168, Hie171, and Thr174 of another monomer of IN.

\section{Conclusion}

The designed molecule AMP_1071 shows topological similarity to LEDGF/p75 binding surface. Further antiviral activity, pharmacokinetic and tolerability studies are ongoing. The LEDGF binding inhibitors lacks the cross resistance to any class of ART, possibly making this class as add on to highly active anti-retroviral therapy.

Published: 27 May 2014

doi:10.1186/1471-2334-14-S3-P18

Cite this article as: Pant et al.: LEDGF/p75 IN interaction inhibitors: in

silico studies of an old target with novel approach. BMC Infectious Diseases 2014 14(Suppl 3):P18.

*Correspondence: amitmpant@gmail.com

Department of Pharmaceutical Sciences, RTM Nagpur University, Nagpur, India

Submit your next manuscript to BioMed Central and take full advantage of:

- Convenient online submission

- Thorough peer review

- No space constraints or color figure charges

- Immediate publication on acceptance

- Inclusion in PubMed, CAS, Scopus and Google Scholar

- Research which is freely available for redistribution 